\title{
Efeitos adversos da toxina botulínica sobre parâmetros ósseos e musculares: revisão integrativa da literatura
}

Adverse effects of botulinic toxin on bone and muscle parameters: integrative literature review Efectos adversos de la toxina botulínica en los parámetros huesos y musculares: revisión integrativa de la literatura

\section{Danielle Sangalli Dalla BARBA ${ }^{1}$}

Gabriela Moraes MACHADO ${ }^{1}$

Myrian Camara BREW ${ }^{2}$

Caren Serra BAVARESCO ${ }^{3}$

'Graduanda do Curso de Odontologia, Curso de Odontologia, Universidade Luterana do Brasil (ULBRA), 92425-020 Canoas - RS, Brasil

${ }^{2}$ Doutora em Biologia Celular e Molecular, Professora do Curso de Odontologia, ULBRA, 92425-020 Canoas - RS, Brasil

${ }^{3}$ Doutora em Bioquímica, Professora do Curso de Odontologia, ULBRA, 92425-020 Canoas - RS, Brasil

\section{Resumo}

Introdução: A toxina botulínica do tipo A tem sido utilizada amplamente como opção terapêutica para o bruxismo. Todavia, é importante discutir o seu efeito nos parâmetros ósseos e musculares. Objetivo: Conhecer, através de revisão integrativa de literatura, os possíveis efeitos adversos da administração terapêutica da toxina botulínica sobre parâmetros ósseos e musculares em modelos animais e humanos. Método: Foi realizada uma busca por artigos nas bases de dados Lilacs, PubMed, Scielo e Google Acadêmico, tendo como descritores os termos "botulinum toxin and bone and masticatory muscles", na língua inglesa e os termos toxina botulínica e osso e músculos mastigatórios, em português. A inclusão dos artigos nesta revisão obedeceu a critérios de inclusão e exclusão. Resultados: Foram encontrados 283 artigos nas bases de dados consultadas, sendo 261 artigos excluídos por título, e nenhum artigo foi excluído por resumoe após sua leitura na íntegra. Um total de 22 artigos fizeram parte desta revisão. Conclusão: Estudos em ratos apontam para alterações esqueléticas e musculares após administração da BTX-A, mesmo comuso único, o que pode resultar em perda óssea a curto e longo prazo e, assim, potencializar problemas futuros. Mais estudos controlados randomizados deveriam ser realizados em humanos para melhores esclarecimentos sobresos efeitos da BTX-A nas estruturas ósseas.

Descritores: Toxinas Botulínicas Tipo A; Osso; Músculos Mastigatórios.

\section{Abstract}

Introduction: Botulinum toxin type A has been widely used as a therapeutic option for bruxism. However, it is important to discuss its effect on bone and muscle parameters. Objective: To know, through an integrative literature review, the possible adverse effects of therapeutic administration of botulinum toxin on bone and muscle parameters in animal and human models. Method: A search for articles was performed in the Lilacs, PubMed, Scielo and Google Scholar databases, using the terms botulinum toxin and bone and masticatory muscles in the English language and the terms "toxina botulínica e osso e músculos mastigatórios", in Portuguese. Inclusion of articles in this review followed inclusion and exclusion criteria. Results: 283 articles were found in the databases consulted, 261 articles excluded by title, and no article was excluded by abstract and after their full reading. A total of 22 articles were part of this review. Conclusion: Studies in rats indicate skeletal and muscular changes after BTX-A administration, even with single use, which may result in short and long term bone loss and, thus, potentialize future problems. Further randomized controlled trials should be performed in humans for further clarification on the effects of BTX-A on bone structures.

Descriptors: Botulinum Toxins, Type A; Bone; Masticatory Muscles.

\section{Resumen}

Introducción: la toxina botulínica tipo A se ha utilizado ampliamente como una opción terapéutica para el bruxismo. Sin embargo, es importante discutir su efecto sobre los parámetros óseos y musculares. Objetivo: Conocer, a través de una revisión bibliográfica integradora, los posibles efectos adversos de la administración terapéutica de toxina botulínica en los parámetros óseos y musculares en modelos animales y humanos. Método: Se realizó una búsqueda de artículos en las bases de datos Lilacs, PubMed, Scielo y Google Scholar, utilizando los términos "toxina botulínica y huesos y músculos masticatorios" como descriptores, en inglés y los términos toxina botulínica y músculos óseos y masticatorios, en portugués. La inclusión de artículos en esta revisión siguió los criterios de inclusión y exclusión. Resultados: Se encontraron 283 artículos en las bases de datos consultadas, 261 artículos fueron excluidos por título, y ningún artículo fue excluido por resumen y después de leerlo en su totalidad. Un total de 22 artículos fueron parte de esta revisión. Conclusión: Los estudios en ratas apuntan a cambios esqueléticos y musculares después de la administración de BTX-A, incluso con un solo uso, lo que puede provocar pérdida ósea a corto y largo plazo y, por lo tanto, mejorar problemas futuros. Se deben realizar más estudios controlados aleatorios en humanos para aclarar mejor los efectos de BTX-A en las estructuras óseas.

Descriptores: Toxinas Botulínicas Tipo A; Huesos; Músculos Masticatorios.

INTRODUÇÃO

A toxina botulínica (BTX) é uma metaloprotease bacteriana produzida pela Clostridium botulinum, bacilo Gram-positivo anaeróbio ${ }^{1}$, comumente encontrada em plantas, em solo, em água e em trato intestinal dos animais. Embora já tenha sido considerada letal, a BTX é atualmente utilizada como um medicamento terapêutico ${ }^{2}$. Ela exibe ações transitórias, não destrutivas, dose-dependentes, com efeitos colaterais sistêmicos pouco estudados $^{2}$. Os sete sorotipos de BTX conhecidos hoje são $A, B, C 1, D, E, F, G$, porém apenas os sorotipos $A(B T X-A)$ e B (BTX-B) estão disponíveis para uso cosmético e terapêutico. O tipo $A$ é o único aprovado para fins cosméticos, sendo também, o mais usado ${ }^{3}$. A BTX-A inicia o efeito entre 24 a 48 horas após a administração e alcança o pico em 2 a 3 semanas, mantendo a sua eficácia por cerca de 3 a 4 meses ${ }^{2}$.

A BTX causa inibição específica da liberação do neurotranmissor acetilcolina em terminações nervosas colinérgicas, impedindo que as vesículas contendo o neurotransmissor sejam liberados na membrana pré-sináptica das junções neuromusculares. Desta forma, não 
ocorre o estímulo na extremidade axônica seguinte, acarretando uma paralisia transitória da placa muscular que é totalmente reversível em alguns meses ${ }^{3,4}$.

O retorno da contração muscular acontece espontaneamente, após aproximadamente 3 meses da administração, por meio de dois processos: o primeiro seria o surgimento de brotos de axônios, ainda na fase inicial; o segundo seria o desenvolvimento de uma nova junção neuromuscular funcional nas terminações nervosas incipientes, substituindo assim a placa motora final ${ }^{1}$.

A BTX vem sendo utilizada principalmente no controle de diferentes condições que envolvem a contração muscular alterada $^{5}$, sendo uma opção terapêutica com variadas indicações clínicas na área da Odontologia, como, por exemplo, 0 hábito parafuncional conhecido por bruxismo ${ }^{6}$.

O bruxismo é uma alteração que apresenta sinais e sintomas clínicos que comprometem as estruturas do sistema estomatognático, gerando dor e desconforto para os pacientes ${ }^{6}$. Lobbezoo et al. ${ }^{7}$ definem 0 bruxismo como uma atividade muscular repetitiva, caracterizada pelo apertamento e/ou rangimento dos dentes. $O$ bruxismo tem duas manifestações circadianas distintas: pode ocorrer durante o sono ou durante a vigília.

Sua etiologia ainda não foi totalmente elucidada, estando os fatores emocionais, alterações do sono, distúrbios neurológicos, uso de medicamentos e algumas condições oclusais citados como desencadeantes deste hábito ${ }^{8}$. 0 bruxismo também frequentemente chama a atenção do parceiro ou de membros da família do paciente, pois os sons do rangido dos dentes muitas vezes são percebidos pela família ${ }^{9}$.

Inúmeras modalidades terapêuticas vêm sendo utilizadas no alívio dos sintomas do bruxismo, como medicamentos, placas oclusais e terapias comportamentais, porém nenhuma delas tem se mostrado totalmente eficiente ${ }^{10}$. Guarda-Nardini et al. ${ }^{11}$ afirmam que a BTX-A pode representar uma promissora alternativa no controle do bruxismo, pois atua na redução da contração dos músculos mastigatórios, principalmente temporal e masseter, e, consequente, na redução da dor dos processos inflamatórios musculares e articulares ${ }^{12}$.

Contudo, esta redução na atividade muscular pode provocar alterações esqueléticas. Estudos em animais identificaram perda óssea após o uso da BTX-A ${ }^{13-15}$. A preocupação com estas possíveis alterações músculo-esqueléticas, provocadas pela redução da atividade muscular induzidos pela BTX-A, deve ser considerada ao optar por seu uso, principalmente por haver um aumento do número de pacientes que são submetidos a estas condutas terapêuticas para controle de dor facial e do bruxismo. Desta forma, o objetivo do presente estudo foi verificar o efeito da administração da BTX-A em parâmetros ósseos e musculares em modelos animais e em humanos através de uma revisão integrativa da literatura.

\section{MATERIAL E MÉTODO}

Para o desenvolvimento deste estudo, foi realizada uma revisão integrativa, utilizando as bases de dados PubMed, Google Acadêmico, Scielo e LILACS, durante os meses de julho a novembro de 2019. Os descritores utilizados foram "Botulinum Toxins, Type $A$ bone and masticatory muscles", na língua inglesa e os termos toxina botulínica e osso e músculos mastigatórios em português. Não foram utilizados filtros para determinar o período de tempo, e somente foram incluídos artigos escritos nas línguas portuguesa, inglesa e espanhola.

Os títulos e resumos de todos os artigos encontrados foram lidos por um pesquisador de forma independente. Os critérios de inclusão foram: artigos originais de dados primários, que utilizavam a TBX, tanto em modelos animais quanto em humanos, com doses aplicadas para tratamento do bruxismo, com desfechos que envolviam parâmetros de remodelamento de tecido ósseo e dos músculos mastigatórios, com ênfase nos efeitos adversos causados pela administração da droga. Os critérios de exclusão foram: revisões de literatura, estudos in vitro, estudos com ênfase no tratamento de bruxismo sem escrever efeitos adversos, estudos que avaliavam a administração estética da TBX.

Ao final da categorização e análise dos estudos, foi realizada a interpretação dos achados, cuja síntese apresenta-se em tabela com autor/país/ano, delineamento do estudo/ amostra, objetivos do estudo e principais resultados.

RESULTADOS E DISCUSSÃO

Foram encontrados 283 artigos nas bases de dados consultadas, sendo 261 artigos excluídos por título, nenhum artigo foi excluído por resumo e os demais foram incluídos na íntegra (Tabela 1).

Foi realizada a interpretação dos estudos que abordavam a avaliação dos efeitos adversos da TBX sobre parâmetros ósseos e musculares. Uma síntese desta interpretação encontra-se na Tabela 2 - estudos em animais 
Tabela 3 - estudos em humanos. A revisão encontrou apenas 2 estudos em humanos, sendo todos realizados em mulheres.

Tabela 1. Seleção dos artigos nas bases de dados

\begin{tabular}{l|c|l|l|l|l|l|}
$\begin{array}{c}\text { Base de } \\
\text { dados }\end{array}$ & Total & $\begin{array}{l}\text { Títulos } \\
\text { excluídos }\end{array}$ & Resumo & $\begin{array}{l}\text { Resumos } \\
\text { excluídos }\end{array}$ & $\begin{array}{l}\text { Leitura } \\
\text { completa }\end{array}$ & Selecionados \\
\hline Lilacs & 0 & 0 & 0 & 0 & 0 & 0 \\
\hline Pubmed & 61 & 39 & 22 & 0 & 22 & 22 \\
\hline $\begin{array}{l}\text { Scielo } \\
\text { Google }\end{array}$ & 0 & 0 & 0 & 0 & 0 & 0 \\
\hline $\begin{array}{l}\text { Acadêmico } \\
\text { Duplicidade }\end{array}$ & & & 0 & 0 & 0 & 0 \\
\hline \begin{tabular}{l} 
Incluídos \\
\hline
\end{tabular} & & & & & \\
\hline
\end{tabular}

Tabela 2. Efeitos adversos da toxina botulínica sobre parâmetros ósseos e musculares em animais, segundo autor/país/ano, amostra, objetivo do estudo

\begin{tabular}{|c|c|c|c|c|}
\hline $\begin{array}{l}\text { Autor/ } \\
\text { País/Ano }\end{array}$ & Amostra & $\begin{array}{l}\text { Objetivo do } \\
\text { estudo }\end{array}$ & $\begin{array}{l}\text { Metodologia/ } \\
\text { Área } \\
\text { investigada }\end{array}$ & $\begin{array}{l}\text { Resultados } \\
\text { Principais }\end{array}$ \\
\hline $\begin{array}{l}\text { Kwon TG et } \\
\text { al. } 2007^{14} \\
\text { Coréia do } \\
\text { Sul }\end{array}$ & $\begin{array}{l}21 \text { coelhos } \\
\text { do sexo } \\
\text { masculino } \\
\cdot\end{array}$ & $\begin{array}{lr}\text { Avaliar } & \text { se } \\
\text { BTX-A pode } \\
\text { alterar os } \\
\text { padrões de } \\
\text { crescimento } \\
\text { esquelético }\end{array}$ & $\begin{array}{l}\text { Os animais } \\
\text { foram divididos } \\
\text { em 3 grupos: } \\
\text { controle e grupos } \\
2 \text { e 3, que foram } \\
\text { injetados com } 5 \\
\text { unidades e } 15 \mathrm{U} \\
\text { BTX-A no } \\
\text { músculo no } \\
\text { masseter direito, } \\
\text { respectivamente } \\
\text { de } \\
\text { coelho. Após } 24 \\
\text { semanas, foram } \\
\text { realizadas as } \\
\text { análises a }\end{array}$ & $\begin{array}{lr}\text { A altura do ramo } \\
\text { mandibular, } \\
\text { comprimento do arco } \\
\text { zigomático e } \\
\text { masseter, após } \\
\text { administração } \\
\text { BTX-A, não de } \\
\text { desenvolveram em } \\
\text { relação ao controle }\end{array}$ \\
\hline $\begin{array}{l}\text { Matic DB et } \\
\text { al. } 2007^{15} \\
\text { EUA }\end{array}$ & $\begin{array}{l}20 \text { coelhos } \\
\text { do sexo } \\
\text { feminino. }\end{array}$ & $\begin{array}{l}\text { Identificar os } \\
\text { efeitos de } \\
\text { BTX-A no } \\
\text { crescimento } \\
\text { ósseo }\end{array}$ & $\begin{array}{lr}\text { A amostra foi } \\
\text { dividida } & \text { em } \\
\text { grupos controle, } \\
\text { paralisia } r \\
\text { simulação. A } \\
\text { paralisia do } \\
\text { músculo } \\
\text { masseter foi } \\
\text { alcançada com a } \\
\text { BTX-A 25U. As } \\
\text { análises finais } \\
\text { foram realizadas } \\
\text { após 12 semanas }\end{array}$ & $\begin{array}{l}\text { Houve diminuições } \\
\text { significativas nos } \\
\text { volumes de zigoma e } \\
\text { mandíbula, mas } \\
\text { mudanças mínimas de } \\
\text { forma foram } \\
\text { observadas nos lados } \\
\text { paralisados }\end{array}$ \\
\hline $\begin{array}{l}\text { Kim JY et } \\
\text { al. } 2008^{16} \\
\text { Coréia do } \\
\text { Sul }\end{array}$ & $\begin{array}{lr}70 & \text { ratos } \\
\text { do } & \text { sexo } \\
\text { masculino } \\
.\end{array}$ & $\begin{array}{l}\text { Investigar os } \\
\text { efeitos do } \\
\text { BTX-A sobre } \\
\text { o } \\
\text { desenvolvimento } \\
\text { mandibular }\end{array}$ & $\begin{array}{l}\text { Quatro grupos: } \\
\text { grupo controle, } \\
\text { grupo salina, } \\
\text { grupo BTX-A } \\
(2,5 \mathrm{U}) \text { e grupo } \\
\text { controle } \\
\text { basal. Os ratos } \\
\text { do grupo basal } \\
\text { foram } \\
\text { sacrificados no } \\
\text { dia o para } \\
\text { fornecer valores } \\
\text { basais das } \\
\text { medidas das } \\
\text { mandibulares. } \\
\text { As avaliações } \\
\text { foram realizadas } \\
\text { após 4 semanas }\end{array}$ & $\begin{array}{l}\text { O grupo BTX-A } \\
\text { demonstrou } \\
\text { diminuição } \\
\text { significativa em } \\
\text { dimensão mandibular } \\
\text { em comparação com } \\
\text { os outros grupos. Suas } \\
\text { cartilagens condilares } \\
\text { apresentaram } \\
\text { aumento de apoptose } \\
\text { e alterações atróficas } \\
\text { nas fibras } \\
\text { massetéricas ras }\end{array}$ \\
\hline $\begin{array}{l}\text { Tsai CY et } \\
\text { al. 200917 } \\
\text { China }\end{array}$ & $\begin{array}{l}8 \text { ratos do } \\
\text { sexo } \\
\text { masculino } \\
\text {. }\end{array}$ & $\begin{array}{l}\text { Avaliar o uso } \\
\text { de BTX-A } \\
\text { sobre o } \\
\text { desenvolvime } \\
\text { nto } \\
\text { craniofacial }\end{array}$ & 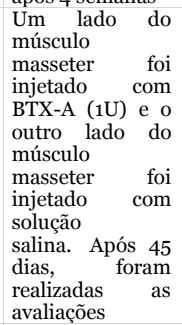 & $\begin{array}{l}\text { O desenvolvimento } \\
\text { craniofacial do lado } \\
\text { injetado BTX-A foi } \\
\text { significativamente } \\
\text { menor do que o lado } \\
\text { não injetado }\end{array}$ \\
\hline $\begin{array}{l}\text { Babuccu et } \\
\text { al. 200918 } \\
\text { Turquia }\end{array}$ & $\begin{array}{lr}48 & \text { ratos } \\
\text { do } & \text { sexo } \\
\text { masculino } \\
\cdot\end{array}$ & $\begin{array}{l}\text { Avaliar a ação } \\
\text { de BTX-A na } \\
\text { formação e } \\
\text { remodelação } \\
\text { óssea }\end{array}$ & $\begin{array}{l}\text { Foi injetado com } \\
1 \text { U de BTX-A em } \\
\text { cada masseter e } \\
\text { temporal } \\
\text { bilateralmente } \\
\text { ou } \\
\text { unilateralmente, } \\
\text { sendo o lado } \\
\text { oposto controle } \\
\text { com solução } \\
\text { salina }\end{array}$ & $\begin{array}{l}\text { Após } 4 \text { meses, os } \\
\text { grupos com BTX-A } \\
\text { apresentaram } \\
\text { diminuição aparente } \\
\text { nas dimensões do osso } \\
\text { nasal, pré-maxila, } \\
\text { maxila e zigomático } \\
\text { no lado injetado }\end{array}$ \\
\hline $\begin{array}{l}\text { Tsai et al. } \\
2010^{19} \\
\text { China }\end{array}$ & $\begin{array}{l}60 \text { ratos } \\
\text { do sexo } \\
\text { masculino }\end{array}$ & $\begin{array}{l}\text { Avaliar o } \\
\text { uso de } \\
\text { BTX-A nos } \\
\text { parâmetros } \\
\text { de } \\
\text { crescimento } \\
\text { ósseo facial }\end{array}$ & $\begin{array}{l}\text { A BTX-A (1U) foi } \\
\text { injetada } \\
\text { bilateralmente } \\
\text { no músculo } \\
\text { masseter do } \\
\text { grupo I, } \\
\text { temporal do } \\
\text { grupo II e n } \\
\text { masseter e } \\
\text { temporal do } \\
\text { grupo III. O } \\
\text { grupo IV foi } \\
\text { utilizado como } \\
\text { controle }\end{array}$ & $\begin{array}{l}\text { Foram observadas } \\
\text { reduções na espessura } \\
\text { óssea cortical e na } \\
\text { densidade mineral } \\
\text { óssea do crânio e } \\
\text { estrutura óssea } \\
\text { mandibular } \\
\text { (Grupo III) }\end{array}$ \\
\hline
\end{tabular}

Tabela 2 (Continuação). Efeitos adversos da toxina botulínica sobre parâmetros ósseos e musculares em animais, segundo autor/país/ano, amostra, objetivo do estudo

\begin{tabular}{|c|c|c|c|c|}
\hline $\begin{array}{l}\text { Autor/ } \\
\text { País/Ano }\end{array}$ & Amostra & $\begin{array}{l}\text { Objetivo do } \\
\text { estudo }\end{array}$ & $\begin{array}{l}\text { Metodologia/ } \\
\text { Área } \\
\text { Investigada }\end{array}$ & $\begin{array}{l}\text { Resultados } \\
\text { Principais }\end{array}$ \\
\hline $\begin{array}{l}\text { Tsai et al. } \\
2010^{20} \\
\text { China }\end{array}$ & $\begin{array}{l}\text { 6o ratos } \\
\text { do sexo } \\
\text { masculino }\end{array}$ & $\begin{array}{l}\text { Utilizar o } \\
\text { crescimento e } \\
\text { desenvolvimento } \\
\text { craniofacial } \\
\text { após injeção } \\
\text { de BTX-A }\end{array}$ & $\begin{array}{l}\text { Os animais } \\
\text { foram divididos } \\
\text { em: I (M + } \\
\text { T); II (Mns + } \\
\text { T); III (M + } \\
\text { T); IV controle, } \\
\text { onde M ou T } \\
\text { são os músculos } \\
\text { masseteres ou } \\
\text { temporais } \\
\text { injetados com } \\
\text { BTX-A (1U). } \\
\text { Após } \\
\text { semanas, foram } \\
\text { realizadas as } \\
\text { análises a }\end{array}$ & $\begin{array}{l}\text { Houve alteração na } \\
\text { face superior, que } \\
\text { ficou curta } \\
\text { acompanhada por } \\
\text { uma face inferior } \\
\text { longa e altura do ramo } \\
\text { e larguras } \\
\text { bicoronoidais e } \\
\text { bigoniais restritas } \\
\text { após injeção com } \\
\text { BTX-A }\end{array}$ \\
\hline $\begin{array}{l}\text { Tsai et al. } \\
2010^{21} \\
\text { China }\end{array}$ & $\begin{array}{l}10 \text { ratos } \\
\text { do sexo } \\
\text { masculino }\end{array}$ & $\begin{array}{l}\text { Avaliar os } \\
\text { efeitos da } \\
\text { BTX-A nos } \\
\text { ossos da } \\
\text { mandíbula }\end{array}$ & $\begin{array}{l}\text { Os seguintes } \\
\text { procedimentos } \\
\text { foram } \\
\text { realizados em } \\
\text { cada amostra: } \\
25 \mathrm{U} \text { de BTX-A } \\
\text { foram injetados } \\
\text { no músculo } \\
\text { masseter } \\
\text { esquerdo, } \\
\text { enquanto o } \\
\text { músculo direito } \\
\text { masseter die } \\
\text { recebeu uma } \\
\text { quantidade } \\
\text { igual de solução } \\
\text { salina } \\
\text { esterilizada }\end{array}$ & $\begin{array}{l}\text { Houve diferenças } \\
\text { significativas na } \\
\text { diminuição da altura } \\
\text { do ramo, aumento do } \\
\text { angulo gonial e } \\
\text { aumento da altura da } \\
\text { coroa dos dentes } \\
\text { posteriores no lado } \\
\text { da injeção após } 95 \\
\text { dias }\end{array}$ \\
\hline $\begin{array}{l}\text { Rafferty et } \\
\text { al. 2012 }{ }^{22} \\
\text { EUA }\end{array}$ & $\begin{array}{l}41 \text { coelhos } \\
\text { do sexo } \\
\text { feminino }\end{array}$ & $\begin{array}{l}\text { Avaliar se o } \\
\text { tratamento } \\
\text { com BTX irá } \\
\text { diminuir a } \\
\text { carga } \\
\text { mandibular }\end{array}$ & $\begin{array}{l}\text { Os coelhos } \\
\text { receberam uma } \\
\text { dose única de } \\
\text { BTX (cada } \\
\text { masseter } \\
\text { injetado recebeu } \\
\text { 1oU ou soro } \\
\text { fisiológico) em } \\
\text { um músculo } \\
\text { masseter } \\
\text { escolhido } \\
\text { aleatoriamente e } \\
\text { foram seguidos } \\
\text { por } 4 \text { ou 12 } \\
\text { semanas }\end{array}$ & $\begin{array}{l}\text { A quantidade e a } \\
\text { qualidade óssea foram } \\
\text { severamente } \\
\text { diminuídas } \\
\text { especificamente } \\
\text { nesses locais com } \\
\text { sobrecarga, } \\
\text { principalmente na } \\
\text { cabeça condilar do } \\
\text { lado da injeção }\end{array}$ \\
\hline $\begin{array}{l}\text { Matthys et } \\
\text { al.2015 } \\
\text { EUA }\end{array}$ & $\begin{array}{l}50 \text { coelhos } \\
\text { do sexo } \\
\text { feminino }\end{array}$ & $\begin{array}{l}\text { Estabelecer } \\
\text { se a perda } \\
\text { óssea no no } \\
\text { côndilo } \\
\text { mandibular é } \\
\text { regionalmente } \\
\text { específica }\end{array}$ & $\begin{array}{l}\text { Foi realizada } \\
\text { injeção de 10U } \\
\text { de BTX-A no } \\
\text { masseter } \\
\text { unilateral ou um } \\
\text { volume } \\
\text { equivalente de } \\
\text { solução salina ou } \\
\text { nenhuma } \\
\text { injeção. Também } \\
\text { foram injetados } \\
\text { com (BrdU), um } \\
\text { marcador de } \\
\text { replicação. Os } \\
\text { coelhos foram } \\
\text { mortos 4 ou 12 } \\
\text { semanas após o } \\
\text { tratamento }\end{array}$ & $\begin{array}{l}\text { Os coelhos com BTX- } \\
\text { A exibiram defeitos na } \\
\text { superfície } \\
\text { condilar. Os ossea } \\
\text { corticais } \\
\text { trabeculares foram } \\
\text { severamente afetados. } \\
\text { O número de células } \\
\text { em proliferação foi } \\
\text { semelhante nos } \\
\text { grupos de tratamento }\end{array}$ \\
\hline $\begin{array}{l}\text { Park et al. } \\
2015^{23} \\
\text { Coréia do } \\
\text { Sul }\end{array}$ & $\begin{array}{l}63 \text { ratos } \\
\text { do sexo } \\
\text { masculino }\end{array}$ & $\begin{array}{l}\text { Avaliar os } \\
\text { efeitos da } \\
\text { BTX-A no } \\
\text { desenvolvimento } \\
\text { esquelético da } \\
\text { mandíbula }\end{array}$ & $\begin{array}{l}\text { Grupo 1- } \\
\text { injetados com } \\
\text { solução } \\
\text { salina; os do } \\
\text { grupo 2 - } \\
\text { injetados } \\
\text { unilateralmente } \\
\text { com BTX-A (3U) } \\
\text { (o lado } \\
\text { contralateral foi } \\
\text { injetado com } \\
\text { solução salina); e } \\
\text { os do grupo 3- } \\
\text { injetados } \\
\text { bilateralmente } \\
\text { com BTX-A. }\end{array}$ & $\begin{array}{l}\text { Após } 4 \text { semanas, no } \\
\text { grupo unilateral, o } \\
\text { lado experimental } \\
\text { teve dimensões } \\
\text { reduzidas para todas } \\
\text { as medidas da } \\
\text { mandíbula em } \\
\text { comparação com o } \\
\text { lado controle }\end{array}$ \\
\hline $\begin{array}{l}\text { Kün- } \\
\text { Darbois et } \\
\text { al..20153 } \\
\text { França }\end{array}$ & $\begin{array}{l}15 \text { ratos do } \\
\text { sexo } \\
\text { masculino }\end{array}$ & $\begin{array}{l}\text { Analisar as } \\
\text { alterações } \\
\text { ósseas após } \\
\text { injeções de } \\
\text { BTX-A }\end{array}$ & $\begin{array}{l}\text { Os ratos do } \\
\text { grupo BTX-A } \\
\text { receberam uma } \\
\text { única injeção de } \\
\text { BTX com 1U no } \\
\text { músculo } \\
\text { masseter e } 1 \mathrm{U} \text { no } \\
\text { músculo } \\
\text { temporal. Os } \\
\text { ratos do grupo } \\
\text { controle foram } \\
\text { injetados de } \\
\text { forma } \\
\text { semelhante com } \\
\text { solução } \\
\text { salina. Os ratos } \\
\text { foram } \\
\text { sacrificados } 4 \\
\text { semanas após as } \\
\text { injeções }\end{array}$ & $\begin{array}{l}\text { Houve perda óssea } \\
\text { significativa nas áreas } \\
\text { alveolar e condilar } \\
\text { direita em ratos } \\
\text { BTX. Uma metaplasia } \\
\text { óssea hipertrófica na } \\
\text { entese do músculo } \\
\text { digástrico foi } \\
\text { encontrada apenas no } \\
\text { grupo BTX }\end{array}$ \\
\hline
\end{tabular}


Tabela 2 (Continuação). Efeitos adversos da toxina botulínica sobre parâmetros ósseos e musculares em animais, segundo autor/país/ano, amostra, objetivo do estudo

\begin{tabular}{|c|c|c|c|c|}
\hline $\begin{array}{l}\text { Autor/ } \\
\text { País/Ano }\end{array}$ & Amostra & $\begin{array}{l}\text { Objetivo do } \\
\text { estudo }\end{array}$ & $\begin{array}{l}\text { Metodologia/ } \\
\text { Área } \\
\text { Investigada }\end{array}$ & $\begin{array}{l}\text { Resultados } \\
\text { Principais }\end{array}$ \\
\hline $\begin{array}{l}\text { Dutra et al. } \\
\text { 2016 } \\
\text { EUA }\end{array}$ & $\begin{array}{l}13 \\
\text { camundon } \\
\text { gos do } \\
\text { sexo } \\
\text { feminino }\end{array}$ & 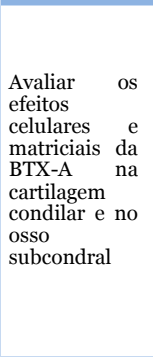 & $\begin{array}{lr}\text { Foi injetado } \\
\text { o,3U de BTX-A } \\
\text { no masseter } \\
\text { direito. } \\
\text { masseter } \\
\text { esquerdo foi } \\
\text { usado romo } \\
\text { controle. } \\
\text { Marcadores } \\
\text { ósseos foram } \\
\text { injetados via } \\
\text { intraperitoneal. } \\
\text { Os ratos foram } \\
\text { sacrificados 30 } \\
\text { dias após injeção } \\
\text { de BTX-A. }\end{array}$ & $\begin{array}{l}\text { O volume ósseo, a } \\
\text { densidade } \mathrm{e} \text { a } \\
\text { espessura trabecular } \\
\text { diminuíram } \\
\text { significativamente no } \\
\text { lado direito do osso } \\
\text { subcondral e na } \\
\text { cartilagem } \\
\text { mineralizada quando } \\
\text { comparado ao lado } \\
\text { esquerdo. }\end{array}$ \\
\hline $\begin{array}{l}\text { Balanta- } \\
\text { Melo } \\
\text { et al. } \\
2017^{25} \\
\text { Chile }\end{array}$ & $\begin{array}{l}16 \\
\text { camundon } \\
\text { gos do } \\
\text { sexo } \\
\text { masculino. }\end{array}$ & $\begin{array}{l}\text { Avaliar as } \\
\text { alterações } \\
\text { microanatôm } \\
\text { icas da } \\
\text { cabeça } \\
\text { mandibular, } \\
\text { após a } \\
\text { intervenção } \\
\text { com o BTX-A }\end{array}$ & $\begin{array}{l}\text { Foi realizada } \\
\text { uma única } \\
\text { injeção } \\
\text { intramuscular de } \\
\text { o,2U de BTX-A } \\
\text { no masseter } \\
\text { direito. O } \\
\text { masseter } \\
\text { contralateral foi } \\
\text { injetado com } \\
\text { solução } \\
\text { salina. Após } 2 \text { ou } \\
4 \text { dias, foram } \\
\text { realizadas } \\
\text { análises no RNA } \\
\text { e no dia 14 } \\
\text { quantificaram-se } \\
\text { os diâmetros das } \\
\text { fibras nas seções } \\
\text { transversais dos } \\
\text { músculos } \\
\text { masseteres por } \\
\text { histomorfometria }\end{array}$ & $\begin{array}{l}\text { Um aumento de até } 4 \\
\text { vezes nos níveis de } \\
\text { mRNA de RANKL nas } \\
\text { cabeças mandibulares } \\
\text { dos lados injetados } \\
\text { com BTX-A. Nas } \\
\text { cabeças inferiores do } \\
\text { lado tratado, a perda } \\
\text { óssea subcondral } \\
\text { houve redução } \\
\text { significativa na área } \\
\text { óssea por tecido e } \\
\text { espessura trabecular }\end{array}$ \\
\hline $\begin{array}{l}\text { Shi et al. } \\
2018^{26} \\
\text { China } \\
(2018) 26\end{array}$ & $\begin{array}{l}\text { 6o ratos } \\
\text { do sexo } \\
\text { feminino }\end{array}$ & $\begin{array}{l}\text { Investigar a } \\
\text { remodelação } \\
\text { condilar após } \\
\text { atrofia do } \\
\text { músculo } \\
\text { masseter }\end{array}$ & $\begin{array}{l}\text { Os animais } \\
\text { foram divididos } \\
\text { em três } \\
\text { grupos:controle, } \\
\text { dieta macia (SD) } \\
\text { e r toxina } \\
\text { botulínica (BTX- } \\
\text { A 2U). Análises } \\
\text { após 4 semanas }\end{array}$ & $\begin{array}{l}\text { Houve hipofunção } \\
\text { muscular nos grupos } \\
\text { SD e BTX e o contorno } \\
\text { da cartilagem condilar } \\
\text { foi diminuído. Uma } \\
\text { osteoporose constante } \\
\text { no osso subcondral foi } \\
\text { encontrada apenas no } \\
\text { grupo BTX. }\end{array}$ \\
\hline $\begin{array}{l}\text { Balanta- } \\
\text { Melo et al. } \\
2019^{27} \\
\text { Chile }\end{array}$ & $\begin{array}{l}18 \\
\text { camundon } \\
\text { gos do } \\
\text { sexo } \\
\text { masculino. }\end{array}$ & $\begin{array}{l}\text { Avaliar a } \\
\text { qualidade } \\
\text { óssea do } \\
\text { côndilo } \\
\text { mandibular e } \\
\text { do processo } \\
\text { alveolar na } \\
\text { mandíbula } \\
\text { após injeção } \\
\text { de BTX-A }\end{array}$ & $\begin{array}{l}\text { Divididos em um } \\
\text { grupo controle } \\
\text { não tratado e um } \\
\text { grupo } \\
\text { experimental o } \\
\text { qual recebeu } \\
\text { uma única } \\
\text { injeção de BTX- } \\
\text { A (o,2U) no } \\
\text { masseter direito } \\
\text { e soro fisiológico } \\
\text { no masseter } \\
\text { esquerdo (salina- } \\
\text { esquerdo). }\end{array}$ & 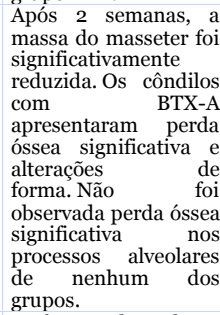 \\
\hline $\begin{array}{l}\text { Dutra et al. } \\
2019^{28} \\
\text { EUA }\end{array}$ & $\begin{array}{l}32 \\
\text { Camundon } \\
\text { gos do } \\
\text { sexo } \\
\text { feminino }\end{array}$ & $\begin{array}{l}\text { Avaliar os } \\
\text { efeitos na } \\
\text { cartilagem } \\
\text { condilar } \\
\text { mandibular e } \\
\text { no osso } \\
\text { subcondilar } \\
\text { após injeção } \\
\text { de BTX-A }\end{array}$ & $\begin{array}{l}\text { Foi injetado } \\
\text { O,3U de BTX-A } \\
\text { no masseter } \\
\text { direito e no } \\
\text { esquerdo foi } \\
\text { utilizado apenas } \\
\text { solução salina. } \\
\text { As análises finais } \\
\text { foram realizadas } \\
\text { após } 8 \text { semanas. }\end{array}$ & 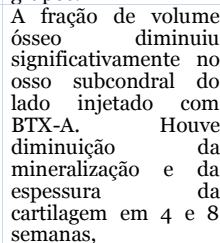 \\
\hline $\begin{array}{l}\text { Choi et al. } \\
2019^{29} \\
\text { Coréia do } \\
\text { Sul }\end{array}$ & $\begin{array}{l}11 \text { ratos do } \\
\text { sexo } \\
\text { masculino }\end{array}$ & $\begin{array}{l}\text { Avaliar } \\
\text { alterações no } \\
\text { plano oclusal } \\
\text { associadas à } \\
\text { hipotrofia dos } \\
\text { músculos } \\
\text { mastigatórios }\end{array}$ & $\begin{array}{l}\text { Os animais } \\
\text { foram tratados } \\
\text { com BTX-A o,3U } \\
\text { nos músculos } \\
\text { masseter } \\
\text { unilateral, } \\
\text { temporal } \\
\text { pterigoideo } \\
\text { medial, com } \\
\text { injeção de } \\
\text { reforço após seis } \\
\text { semanas para o } \\
\text { grupo } \\
\text { experimental. O } \\
\text { grupo controle } \\
\text { recebeu solução } \\
\text { salina bilateral }\end{array}$ & $\begin{array}{l}\text { Após } 12 \text { semanas, os } \\
\text { músculos masseter e } \\
\text { pterigoideo medial no } \\
\text { lado do BTX-A } \\
\text { apresentaram } \\
\text { alteração } \\
\text { hipotrófica. Os } \\
\text { molares superiores e } \\
\text { inferiores foram supra } \\
\text { eruptados do plano de } \\
\text { Frankfort }\end{array}$ \\
\hline $\begin{array}{l}\text { Tsai et al. } \\
2019^{30} \\
\text { China }\end{array}$ & $\begin{array}{l}48 \text { ratos do } \\
\text { sexo } \\
\text { masculino }\end{array}$ & 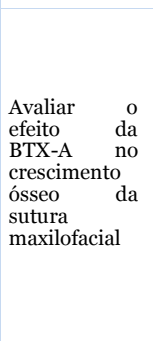 & $\begin{array}{l}\mathrm{O} \text { grupo N } \mathrm{N} \\
\text { recebeu injeções } \\
\text { de solução salina } \\
\text { em cada um dos } \\
\text { músculos } \\
\text { masseter e e } \\
\text { temporal. O } \\
\text { grupo M recebeu } \\
\text { injeções de } \\
\text { solução salina } \\
\text { normal em cada } \\
\text { temporal e } \\
\text { injeçôes de BTX- } \\
\text { A (1U) em cada } \\
\text { masseter }\end{array}$ & $\begin{array}{l}\text { Houve diminuições } \\
\text { significativas no peso } \\
\text { muscular, medidas } \\
\text { antropométricas, } \\
\text { densidade mineral } \\
\text { óssea sutural a } \\
\text { distância de aposição } \\
\text { óssea no grupo } \\
\text { injetado com BTX-A }\end{array}$ \\
\hline
\end{tabular}

Tabela 3. Efeitos adversos da toxina botulínica sobre parâmetros ósseos e musculares em humanos, segundo autor/país/ano, delineamento e amostra, objetivo do estudo, metodologia/área investigada e resultados principais

\begin{tabular}{|c|c|c|c|c|}
\hline $\begin{array}{l}\text { Autor/ } \\
\text { País/Ano }\end{array}$ & Amostra & $\begin{array}{l}\text { Objetivo do } \\
\text { estudo }\end{array}$ & $\begin{array}{l}\text { Metodologia/ } \\
\text { Área } \\
\text { investigada }\end{array}$ & $\begin{array}{l}\text { Resultados } \\
\text { Principais }\end{array}$ \\
\hline $\begin{array}{l}\text { Raphael et } \\
\text { al. 201431 } \\
\text { EUA }\end{array}$ & $\begin{array}{l}16 \\
\text { mulheres }\end{array}$ & $\begin{array}{l}\text { Examinar as } \\
\text { consequência } \\
\text { s de BTX-A } \\
\text { nos músculos } \\
\text { mastigatórios }\end{array}$ & $\begin{array}{l}7 \text { pacientes com } \\
\text { DTM que } \\
\text { receberam 2 ou } \\
\text { mais sessóes de } \\
\text { tratamento com } \\
\text { BTX-A para dor } \\
\text { facial e g } \\
\text { pacientes com } \\
\text { DTM que não } \\
\text { receberam } \\
\text { tratamento com } \\
\text { BTX-A }\end{array}$ & $\begin{array}{l}\text { Ambos } \\
\text { avaliadores } \\
\text { observaram } \\
\text { diminuição da } \\
\text { densidade em todos } \\
\text { os participantes } \\
\text { expostos ao BTX-A } \\
\text { e em nenhum dos } \\
\text { participantes não } \\
\text { expostos. Nenhuma } \\
\text { outra anormalidade } \\
\text { associada à carga } \\
\text { reduzida } \\
\text { detectada }\end{array}$ \\
\hline $\begin{array}{l}\text { Kahn et al. } \\
2019^{32} \\
\text { França }\end{array}$ & $\begin{array}{l}12 \\
\text { pacientes } \\
\text { (10 } \\
\text { mulheres } \\
\text { e } 2 \\
\text { homens) }\end{array}$ & $\begin{array}{l}\text { Avaliar a } \\
\text { mandíbula de } \\
\text { pacientes que } \\
\text { receberam de } \\
\text { injeções de } \\
\text { BTX-A nos } \\
\text { músculos } \\
\text { mastigatórios } \\
\text {. }\end{array}$ & $\begin{array}{l}\text { Seis pacientes } \\
\text { que não } \\
\text { receberam } \\
\text { injeções de BTX- } \\
\text { A foram usados } \\
\text { como } \\
\text { controle/regiões } \\
\text { condilares e } \\
\text { alveolares da } \\
\text { mandíbula. Cada } \\
\text { paciente recebeu } \\
\text { uma dose total } \\
\text { de 10oU-3oU no } \\
\text { masseter e 2oU } \\
\text { para } \\
\text { músculo cada } \\
\text { temporal }\end{array}$ & $\begin{array}{l}\text { Após } 12 \text { meses, um } \\
\text { afinamento cortical } \\
\text { significativo } \\
(\mathrm{P}<0,001) \\
\text { encontrado foi } \\
\text { porção anterior do } \\
\text { côndilo direito. Não } \\
\text { foram encontradas } \\
\text { alterações nos } \\
\text { ângulos } \\
\text { mandibulares }\end{array}$ \\
\hline
\end{tabular}

Atualmente, a BTX-A tem sido utilizada para aplicações cosméticas e terapêuticas em uma ampla gama de situações clínicas. Inicialmente utilizada para 0 tratamento de estrabismo, o BTX-A mostrou-se eficaz no tratamento de alterações caracterizadas pela hiperatividade muscular local, tal como ocorre no bruxismo. Desde a aprovação do seu uso pela Food and Drug Administration (FDA) em 1989, a BTX-A tem sido amplamente utilizada na Odontologia para o tratamento de desordens funcionais e estéticas ${ }^{19}$ tais como a nevralgia do trigêmeo, síndrome da dor miofacial ${ }^{2}$, bruxismo, hipertrofia do masseter ${ }^{4,20}$, hipersalivação, controle de traumas mastigatórios e apertamento dentário em pacientes que farão reabilitação com implantes ${ }^{2}$, além de minimizar marcas de expressão e correção de assimetrias faciais $^{2,19}$. Todavia, muito pouco ainda tem sido discutido em relação aos possíveis efeitos adversos decorrentes do uso da BTX-A.

Embora a paralisia seja transitória, ainda não estão totalmente elucidados os mecanismos fisiológicos associados ao retorno da atividade funcional do músculo que recebeu a BTX-A. Por muito tempo, acreditou-se que a ação da BTX-A era local; todavia estudos recentes têm demonstrado ação negativa da administração massetérica da BTX-A no sistema nervoso central. Estudo realizado por Tsai et al. $^{30}$ demonstrou uma redução significativa na densidade de neurônios nos ratos injetados com TBX-A por via intramuscular. Por outro lado, FukushimaNakayama et al. ${ }^{33}$ mostraram que a mastigação 
reduzida resultou em prejuízo da memória espacial e da função de aprendizado devido à alteração morfológica e à diminuição da atividade no hipocampo. Nesse estudo, a ligação funcional entre mastigação e cérebro foi validada pela diminuição dos neurônios, neurogênese, atividade neuronal e expressão do brain-derived neurotrophic factor (BDNF) no hipocampo. Esses achados, em conjunto, fornecem evidências in vivo para uma ligação funcional entre a mastigação e a função cognitiva no período de crescimento.

Quando se direciona especificamente à sua ação sobre os parâmetros ósseos e musculares, é necessário elucidar alguns aspectos da fisiologia óssea mandibular.

A mandíbula é uma estrutura esquelética composta de osso alveolar e basal, sendo esses constituídos por tipo ósseo medular e cortical, respectivamente. $\mathrm{O}$ osso alveolar tem alta plasticidade e relativo potencial de remodelação. Sua estimulação mecânica durante a mastigação é essencial para manter os dentes e ossos subjacentes saudáveis; contudo, a perda dentária pode acarretar uma reabsorção óssea alveolar irreversível ${ }^{3}$. A carga mecânica muscular é fundamental para manutenção da arquitetura óssea e, dessa forma, a diminuição ou ausência dos movimentos e carregamento funcional podem alterar ou reduzir a morfologia esquelética ${ }^{4}$.

Os estudos apresentados apontam que o uso da BTX-A em animais pode causar alterações anatômicas ${ }^{14,15,17,19-21}$, como alterações no osso nasal, pré-maxila e maxila, ${ }^{18}$ osteopenia do ramo mandibular ${ }^{419,20,22,24,28}$, osso alveolar e do osso subcondral, bem como a redução significativa do volume ósseo, da densidade do tecido e da espessura trabecular, quando comparado ao grupo que não recebeu a drog ${ }^{22,24}$. Ademais, também foi observado aumento da coroa em dentes posteriores ${ }^{21,22,29} \mathrm{e}$ metaplasia óssea hipertrófica na entese do músculo digástrico, que é um fator de risco para fraturas ${ }^{3}$.

Quando observadas as questões musculares, foi possível observar que as injeções intramusculares de BTX-A levavam a uma rápida diminuição da força de contração e uma lenta redução da massa muscular, como demonstrado no estudo de Rauch et al. ${ }^{13}$. Resultado semelhante foi observado no estudo de Rafferty et al. $^{22}$ que encontrou redução de $7 \%$ da massa muscular do masseter após a administração da BTX-A.

Em humanos, foi observado diminuição da densidade óssea, afinamento cortical, alterações no osso condilar e na fossa digástrica ${ }^{32,34}$.

$\mathrm{Na}$ presente revisão, foi possível observar que os estudos mostraram alterações ósseas e musculares associadas ao uso da droga, principalmente em animais em desenvolvimento. Assim, cabe à Odontologia discutir cuidadosamente os protocolos de indicação terapêutica, avaliando o risco/benefício da sua aplicação.

CONCLUSÃO

A utilização de BTX dentro da Odontologia está cada vez mais difundida entre os profissionais de saúde e aceito pelos pacientes. Todavia, devem-se considerar as evidências que indicam alterações ósseas e musculares significativas após o uso desta droga. Ainda, poucos foram os estudos encontrados que avaliassem seu uso e possíveis efeitos adversos em humanos. A revisão encontrou apenas 2 estudos e todos realizados com mulheres. Sugere-se que mais estudos sejam realizados para melhor compreensão dos efeitos adversos oriundos da administração da BTX.

\section{REFERÊNCIAS}

1. Dutta SR, Passi $D$, SinghM, Singh $P$, Sharma $S$, Sharma A. Botulinum toxin the poison that heals: A brief review. Natl J MaxillofacSurg. 2016;7(1):10-6.

2. Archana MS. Toxin yet not toxic: Botulinum toxin in dentistry. Saudi Dent J.2016;28(2):63-9.

3. Kün-Darbois JD, Libouban $\mathrm{H}$, Chappard $\mathrm{D}$. Botulinum toxin in masticatory muscles of the adult rat induces bone loss at the condyle and alveolar regions of the mandible associated with a bone proliferation at a muscle enthesis. Bone. 2015;77:75-82.

4. Matthys $T$, Ho Dang HA, Rafferty KL, Herring $\mathrm{SW}$. Bone and cartilage changes in rabbit mandibular condy lesafter 1 injection of botulinum toxin. Am J Orthod Dentofacial Orthop. 2015;148(6):999-1009.

5. Wheeler A \& Smith H S. Botulinum toxins: Mechanisms of action, antinociception and clinical applications. Toxicology. 2013;306: 124-46.

6. Monte MN, Soares MGM. Bruxismo: etiologia e epidemiologia. Rev CROMG. 2002;8(1):43-8.

7. Lobbezoo F, Ahlberg J, Glaros AG, Kato T, Koyano K, Lavigne GJ. Bruxism defined and graded: aninternational consensus. J Oral Rehabil. 2012;40(1):2-4.

8. Gaida PS. Bruxismo um desafio para a odontologia [monografia]. Florianópolis: Departamento de Centro de Ciências da Saúde, UFSC; 2004. 
9. Bader G, Lavigne G. Sleep bruxism; an overview of an oromandibular sleep movement disorder. Sleep Med Rev. 2000;4(1):27-43.

10. Lobbezoo F, van der Zaag J, van Selms MK, Hamburger HL, Naeije M. Principles for the management of bruxism. J Oral Rehabil. 2008;35(7):509-23.

11. Guarda-Nardini L, Manfredini D, Salamone M, Salmaso L, Tonello S, Ferronato G. Efficacy of botulinum toxin in treating myofascial pain in bruxers: a controlled placebo pilot study. Cranio. 2008;26(2):126-35.

12. Colhado OCG, Boeing M, Ortega LB. Toxina botulínica no tratamento da dor. Rev Bras Anestesiol. 2009;59(3):366-81.

13. Rauch F, Hamdy R. Effect of a single botulinum toxin injection on bone development in growing rabbits. J Musculoskelet Neuronal Interact. 2006;6(3):264-68.

14. Kwon TG, Park HS, Lee SH, Park IS, An CH. Influence of unilateral masseter muscle atrophy on craniofacial morphology in growing rabbits. $\mathrm{J}$ Oral Maxillofac Surg. 2007;65(8):1530-37.

15. Matic DB, Yazdani A, Wells RG, Lee TY, Gan $B S$. The effects of masseter muscle paralysis on facial bone growth. J Surg Res. 2007;139(2):243-52.

16. Kim JY, Kim ST, Cho SW, Jung HS, Park KT, Son HK. Growth effects of botulinum toxin type A injected into masseter muscle on a developing rat mandible. Oral Dis. 2008;14(7):626-32.

17. Tsai CY, Chiu WC, Liao YH, Tsai CM. Effects on craniofacial growth and development of unilateral botulinum neurotoxin injection into the masseter muscle. Am J Orthod Dentofacial Orthop. 2009;135(2):142.e1-6.

18. Babuccu B, Babuccu O, Yurdakan G, Ankarali $H$. The effect of the Botulinum toxin-A on craniofacial development: an experimental study. Ann Plast Surg. 2009;63(4):449-56.

19. Tsai CY, Shyr YM, Chiu WC, Lee CM. Bone changes in the mandible following botulinum neurotoxin injections. Eur $\mathrm{J}$ Orthod. 2011;33(2):132-38.

20. Tsai CY, Wang CW, Chang CW. Effects of masticatory muscle function affected by BTX on maxillofacial bone growth through the sutural modification. OrthodCraniofac Res. 2019;22(2): 112-17.

21. Tsai CY, Yang LY, Chen KT, Chiu WC. The influence of masticatory hypofunction on developing rat craniofacial structure. Int J Oral MaxillofacSurg. 2010;39(6):593-98.

22. Rafferty KL, Liu ZJ, Ye W, Navarrete AL, Nguyen TT, Salamati $A$ et al. Botulinum toxin in masticatory muscles: short- and long-term effect son muscle, bone, and craniofacial function in adultrabbits. Bone. 2012;50(3): 651-62.
23. Park C, Park K, Kim J. Growth effects of botulinum toxin type A injected unilaterally in to the masseter muscle of developing rats. J Zhejiang Univ Sci B. 2015;16(1):46-51

24. Dutra $E H, O^{\prime}$ Brien $M H$, Lima A, Kalajzic Z, Tadinada A, Nanda $R$ et al. Cellularand Matrix Response ofthe Mandibular Condylar Cartilage to Botulinum Toxin. PLoSOne. 2016;11(10): e0164599.

25. Balanta-Melo J, Toro-Ibacache V, TorresQuintana MA, Kupczik K, Vega C, Morales C et al. Early molecular response and micro anatomical changes in the masseter muscle and mandibular head after botulinum toxin intervention in adult mice. Ann Anat. 2018;216: 112-19.

26. Shi Z, Lv J, Xiaoyu L, Zheng LW, Yang XW. Condylar Degradation from Decreased Occlusal Loading following Masticatory Muscle Atrophy. Biomed Res Int. 2018;2018:6947612.

27. Balanta-Melo J, Torres-Quintana MA, Bemmann M, Vega C, González C, Kupczik K et al. Masseter muscle atrophy impairs bone quality of the mandibular condyle but not the alveolar process early after induction. J Oral Rehabil. 2019;46(3):233-41.

28. Dutra EH, Yadav S. The effects on the mandibular condyle of Botox injection in to the masseter are not transient. Am J Orthod Dentofacial Orthop. 2019;156(2):193-202.

29. Choi JW, Kim HJ, Moon JW, Kang SH, Tak HJ, Lee $\mathrm{SH}$. Compensatory dentoalveolar supra eruption and occlusal plane cant after botulinum-induced hypotrophy of masticatory closing muscles in juvenile rats. Arch Oral Biol. 2019;101:34-42.

30.Tsai CY, Wang CW, Chang CW. Effects of masticatory muscle function affected by BTX on maxillofacial bone growth through the sutural modification. Orthod Craniofac Res. 2019;22(2): 112-17.

31. Raphael KG, Tadinada A, Bradshaw JM, Janal $\mathrm{MN}$, Sirois DA, Chan KC et al. Osteopenic consequences of botulinum toxin injections in the masticatory muscles: a pilot study. J Oral Rehabil. 2014;41(8):555-63.

32. Kahn A, Kün-Darbois JD, Bertin $H$, Corre $P$, Chappard D. Mandibular bone effects of botulinum toxin injections in masticatory muscles in adult. Oral Surg Oral Med Oral Pathol Oral Radiol. 2020;129(2):100-8.

33. Fukushima-Nakayama $Y$, Ono $T$, Hayashi $M$, Inoue $\mathrm{M}$, Wake $\mathrm{H}$, Ono $\mathrm{T}$, Nakashima $\mathrm{T}$. Rduced Mastication Impairs Memory Function. J Dent Res. 2017;96(9):1058-66.

34.Dutra EH, Yadav S. The effects on the mandibular condyle of Botox injection in to the masseter are not transient. Am J Orthod Dentofacial Orthop. 2019;156(2):193-202. 


\section{CONFLITO DE INTERESSES}

Os autores declaram não haver conflitos de interesse

\section{AUTOR PARA CORRESPONDÊNCIA}

\section{Danielle Sangalli Dalla Barba}

Rua Maurício Cardoso 1555, apto 804

93510-335 Novo Hamburgo-RS, Brasil

Fone: (51) 99759-7111

Email: dani_dallab@hotmail.com 